\title{
Sistem Informasi Penggajian Karyawan Radaksi Papua Barat Pos Berbasis Desktop
}

\author{
Frits Gerit John Rupilele ${ }^{1 *}$, Carlie P. Sibarani ${ }^{2}$ \\ 1,2 Universitas Victory Sorong \\ Email: ${ }^{1}$ fritsrupilele@gmail.com*
}

\begin{abstract}
Abstrak
Kemajuan Teknologi Informasi telah menjadi keputusan utama dalam membuat Sistem Informasi hierarkis yang solid sehingga dapat unggul dan menjadi prosedur yang tak tertandingi di tengah persaingan yang semakin ketat saat ini. Namun, pengembangan Sistem Informasi suatu organisasi tidak hanya untuk mengotomatisasi sebagian dari siklus yang dilakukan secara teratur, melainkan menghasilkan sesuatu aliran informasi yang baru yang secara sistematis serta terintegrasi disusun menjadi suatu sistem yang terpadu. Penggajian merupakan membagikan kompensasi buat pegawai yang berbentuk pendapatan selaku kembalian finansial kepada para pegawai sebagai kontribusi mereka terhadap organisasi, institusi ataupun lembaga. Setiap perusahaan termasuk Papua Barat Pos, yang memiliki banyak karyawan, tentu harus memperhitungkan penggajian karyawan dengan cepat dan benar agar tidak timbul masalah di lingkungan perusahaan akibat adanya kecurangan ataupun human error. Sehingga, perusahaan Papua Barat Pos memerlukan sebuah sistem informasi penggajian yang sekaligus dapat melakukan cetak slip gaji secara otomatis. Dengan dibuatnya "Sistem Informasi Penggajian Karyawan Papua Barat Pos Berbasis Desktop" ini, diharapkan kebutuhan perusahaan akan pencatatan penggajian dapat terpenuhi dengan baik.
\end{abstract}

Kata kunci: Sistem Informasi Penggajian, Desktop

\section{West Papua Post's Employee Salary Information System Desktop Based}

\begin{abstract}
Advances in Information Technology have become the main decision in creating a solid hierarchical Information System so that it can excel and become an unmatched procedure in the midst of increasingly fierce competition today. However, the development of an organization's Information System is not only to automate some of the cycles that are carried out regularly, but to produce a new flow of information that is systematically and integratedly arranged into an integrated system. Payroll is distributing compensation for employees in the form of income as a financial return to employees as their contribution to the organization, institution or institution. Every company, including Papua Barat Pos, which has many employees, must of course take into account employee payroll quickly and correctly so that problems do not arise in the company environment due to fraud or human error. Thus, the West Papua Pos company needs a payroll information system that can also print payslips automatically. With the creation of the "Desktop-Based Postal West Papua Employee Payroll Information System", it is hoped that the company's need for payroll records can be fulfilled properly.
\end{abstract}

Keywords: Payroll Information System, Desktop

\section{PENDAHULUAN}

Perkembangan ilmu pengetahuan dan teknologi pada saat ini mempunyai peranan yang sangat penting bagi masyarakat untuk bekerja maupun beraktivitas sehari-hari. Begitu pula dalam bidang bisnis, pertumbuhan teknologi sangat menunjang para pengusaha dalam melaksanakan usaha mereka sehingga fasilitas yang efisien buat mengakses, mengolah serta menyimpan sumber informasi yang sudah mejadi bagian yang tidak terpisahkan dalam aktivitas usaha.

Teknologi Informasi telah jadi opsi utama dalam menghasilkan Sistem Informasi organisasi yang tangguh sehingga sanggup melahirkan keunggulan kompetitif serta jadi strategi unggulan di tengah persaingan yang terus menjadi ketat saat ini. Namun pembangunan Sistem Informasi suatu organisasi bukan sekedar mengotomatisasi sebagian proses yang secara rutin dilakukan, melainkan 
menciptakan suatu aliran informasi yang baru yang secara sistematis dan terintegrasi disusun menjadi suatu sistem yang terpadu[1].

Penggajian merupakan membagikan kompensasi buat pegawai yang berbentuk pendapatan selaku kembalian finansial kepada para pegawai sebagai kontribusi mereka terhadap organisasi, institusi ataupun lembaga [2]. Institusi yang menjadi objek dalam penelitian ini adalah Papua Barat Pos yang merupakan sebuah lembaga yang menyediakan berita aktual seputar keadaan yang terjadi khususnya di daerah Sorong, Papua Barat. Saat ini institusi tersebut belum mengimplementasikan suatu sistem informasi penggajian karyawan sehingga sistem penggajian masih dilakukan secara manual menggunakan Microsoft Word dan perhitungan kalkulator.

Sistem Informasi Penggajian Karyawan sangat berguna, sehingga sistem tersebut wajib didesain dengan baik supaya bisa memberikan layanan yang diperlukan dan bisa menunjang membagikan informasi dalam wujud laporan, hal ini butuh didukung oleh sistem informasi yang sanggup sediakan data secara cepat serta akurat mengingat penggajian merupakan salah satu proses dalam organisasi yang rentan terhadap permasalahan. Kesalahan perhitungan ataupun keterlambatan pembayaran pendapatan ialah contoh permasalahan yang kerap dialami dalam sistem penggajian.

Berdasarkan latar belakang tersebut, maka dilakukan penelitian dengan judul "Sistem Informasi Penggajian Karyawan Papua Barat Pos Berbasis Desktop”, yang diharapkan dapat membantu pengelolaan penggajian di Papua barat Pos, serta mempermudah pihak keuangan perusahaan dalam melakukan perhitungan penggajian dan mendapatkan hasil cetak slip gaji secara otomatis serta akurat yang dihasilkan dari pengolahan data yang ada. Setiap modul yang terdapat pada sistem ini akan disesuaikan berdasarkan kebutuhan penggajian serta pencetakan slip gaji bagi karayawan.

\section{METODE}

\subsection{Metode Protoryping}

Pengembangan sistem dalam penelitian menggunakan metode prototyping. Metode ini merupakan salah satu metode pengembangan perangkat lunak yang banyak digunakan untuk interaksi antara pembuat aplikasi dan pengguna aplikasi selama proses pembuatan sistem [3]. Dalam penggunaannya, biaya dan jadwal disesuaikan berdasarkan umpan balik yang disimpulkan dari hasil evaluasi pelanggan. Pilihan untuk menggunakan metode prototype dengan alasan yaitu metode ini dapat digunakan untuk mengelola kembali kebutuhan dari perangkat lunak yang akan dikembangkan, sehingga pengembangan perangkat lunak tidak harus merancang lagi semua dari awal. Model metode prototype ditunjukkan pada Gambar 1.

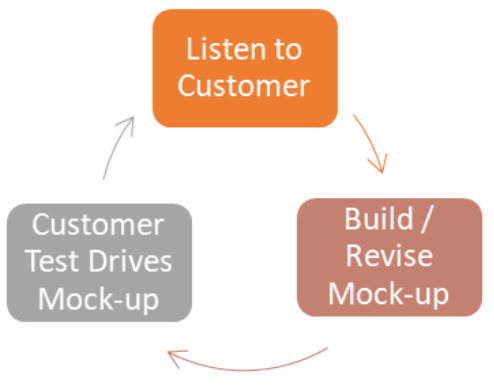

Gambar 1. Prototyping Model

Berikut ini adalah tahap-tahap dalam penggunaan metode prototyping:

1. Listen to Customer.

Pada tahapan ini, dilakukan analisa secara menyeluruh atas kebutuhan apa saja yang diperlukan dalam perancangan perangkat lunak. Analisa kebutuhan untuk pengembangan Sistem Informasi Penggajian Karyawan Papua Barat Pos Berbasis Desktop dilakukan dengan cara melakukan penelitian dan wawancara terhadap pihak kantor redaksi Papua Barat Pos. Dari hasil wawancara, dapat diketahui bahwa sistem penggajian yang digunakan masih menggunakan cara manual yakni dengan pembukuan. Dari hasil penelitian dan wawancara ini juga dapat diketahui kebutuhan-kebutuhan yang diperlukan dalam perancangan dan pengembangan sistem informasi penggajian.

Kebutuhan yang diperlukan dari hasil analisa adalah sebagai berikut.

a. Aktor yang terdapat pada sistem informasi penggajian adalah administrator.

b. Peranan administrator adalah sebagai petugas khusus yang dapat melakukan manajemen data. Dalam hal ini, seorang administrator juga harus memiliki pengetahuan cukup tentang komputer, Visual Basic .Net, dan database sistem.

c. Terdapat beberapa proses dalam pengembangan sistem ini yaitu proses penyimpanan data dan proses manajemen data.

2. Build / Revise Mock-up.

Pada tahapan ini dilakukan proses perancangan sistem sementara yang berfokus pada penyajian rancangan dengan membuat format input dan output berupa diagram dan perancangan tampilan antarmuka sistem. Pada tahap ini, diberikan 
gambaran kepada user dan khususnya kepada pembangun prototyping dalam mengembangkan aplikasi desktop ataupun sistem yang akan dibangun dengan menggunakan Bahasa Pemrograman Visual Basic .Net dan SQL Server.

3. Customer Tes-Drives Mock-up. Pada tahapan ini dilakukan proses pengujian sistem oleh user sesuai dengan tujuan pembuatan sistem. Dari tahapan ini akan diperoleh kekurangan atau kesalahan yang ada pada prototyping yang sudah dibangun. Proses ini merupakan proses yang sangat penting, karena akan bermanfaat saat dilakukan pengembangan sistem.

\subsection{Analisis Kebutuhan Sistem}

Dalam perancangan sistem proses dimulai dari identifikasi informasi mengenai kebutuhan pengguna seperti informasi apa saja yang perlu disajikan kepada karyawan Papua barat Pos. Berdasarkan latar belakang masalah yang terdapat dalam bab 1 pada penelitian ini dapat diidentifikasikan bahwa sistem perusahaan sebelumnya, proses pencatatan gaji karyawan masih dilakukan secara manual. Pada proses penggajian perusahaan yang menggunakan pencatatan gaji secara manual menyebabkan proses transaksi gaji yang mereka lakukan menjadi kurang efisien. Berdasarkan latar belakang tersebut permasalahan yang timbul dapat disimpulkan sebagai berikut:

1. Sistem informasi penggajian yang akan dibuat harus dapat diintegrasikan dengan sistem informasi lain milik Papua barat Pos agar dapat menghasilkan informasi yang dibutuhkan dengan tepat.

2. Dalam pencatatan gaji karyawan secara manual menyebabkan pengelolaan sistem penggajian perusahaan menjadi kurang efisien. Hal ini disebabkan karena adanya kemungkinan terjadinya human error atau kecurangan oleh pihak tidak bertanggung jawab saat melakukan pembukuan.

3. Pimpinan mengalami kesulitan dalam memeriksa laporan rinci penggajian karyawan. Laporan dalam bentuk kertas dengan banyaknya karyawan pastinya membuat repot.

Dari permasalahan yang timbul di atas dapat ditarik kesimpulan bahwa pencatatan gaji karyawan secara manual dapat menyebabkan proses pembuatan laporan yang akan diserahkan kepada pimpinan menjadi lambat dan repot, maka sistem informasi penggajian ini akan membantu melakukan pengelolaan gaji karyawan di Papua barat Pos, serta mempermudah pihak keuangan perusahaan dalam melakukan perhitungan penggajian dan mendapatkan hasil cetak slip gaji secara otomatis serta akurat yang dihasilkan dari pengolahan data yang ada. Setiap modul yang terdapat pada sistem ini akan disesuaikan berdasarkan kebutuhan penggajian serta pencetakan slip gaji bagi karayawan.

\subsection{Perancangan Sistem}

Dalam pembuatan sebuah sistem, dibutuhkan pemahaman dasar mengenai rancangan dan alur kerja sistem untuk mempermudah pembuatan sistem untuk setiap bagian yang akan dibuat. Setelah dilakukan identifikasi kebutuhan sistem yang akan dirancang, pada subbab desain sistem ini akan dijelaskan Unified Modeling Language (UML) diagram yang meliputi use case diagram, activity diagram, class diagram, dan sequence diagram untuk mempermudah memahami alur kerja sistem.

\section{Use Case Diagram}

Use case diagram menggambarkan fungsionalitas yang diharapkan dari sebuah sistem. Sebuah sistem mempresentasikan sebuah interaksi antara aktor dengan sistem. Pada tahap ini akan dijelaskan interaksi yang dilakukan oleh aktor-aktor yang terdapat pada sistem yang dirancang [4]-[7].

Use case diagram pada aplikasi ini terdiri dari dua aktor yakni administrator dan user. Setiap aktor memiliki peran yang berbeda pada penggunaan aplikasi ini. Use case diagram ditunjukkan pada Gambar 3.2.

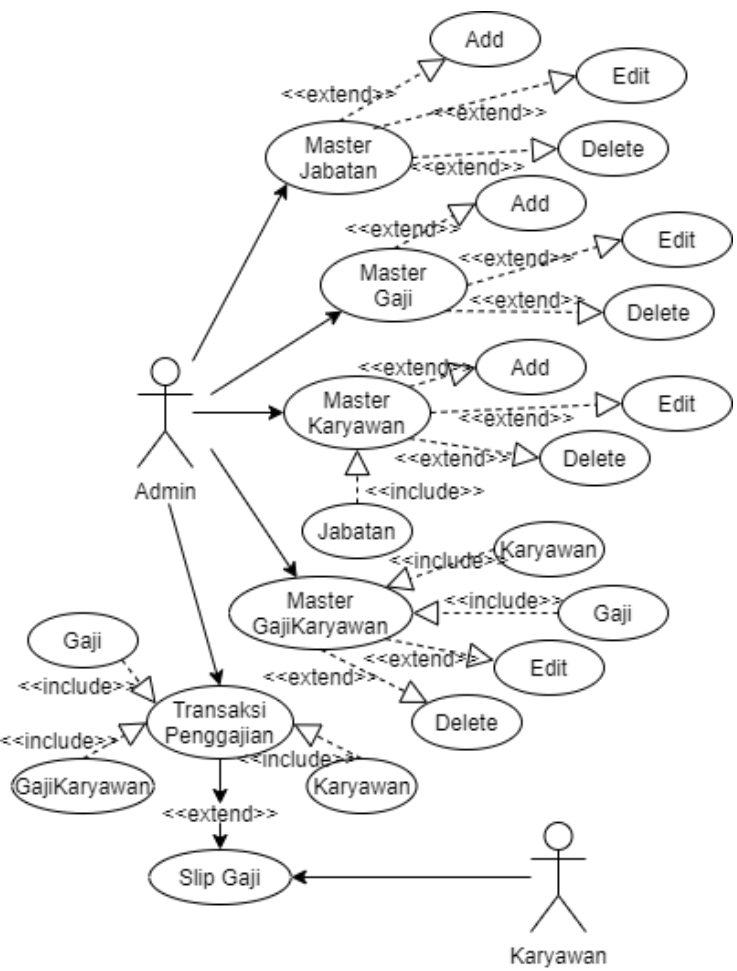

Gambar 2. Use Case Diagram

Pada Gambar 3.2, administrator bertindak sebagai aktor yang mempunyai hak mengelola 
data yaitu dengan menambah, mengubah maupun menghapus data individu pegawai, data gaji serta membuat laporan.

Karyawan merupakan aktor yang berhak mendapatkan laporan dari administrator untuk kemajuan dari lembaga yang di pimpinnya. Yang menjadi penghubung dua aktor di atas adalah use case Transaksi Gaji dan use case Karyawan.

\section{Activity Diagram}

Activity diagram menggambarkan berbagai alir aktivitas dalam sistem yang sedang dirancang, bagaimana masing-masing alir berawal, decision yang mungkin terjadi, dan bagaimana mereka berakhir [4], [8].

Activity diagram juga dapat menggambarkan proses paralel yang mungkin terjadi pada beberapa eksekusi. Activity diagram merupakan pengembangan dari use case diagram. Activity diagram menunjukkan alur kerja dari aktivitas atau kegiatan yang dilakukan di dalam use case diagram.

Activity diagram ini terdapat swimline yang berfungsi sebagai garis pembatas antara aktivitas satu dengan aktivitas lainnya. Activity diagram administrator ditunjukkan pada Gambar 3.3.

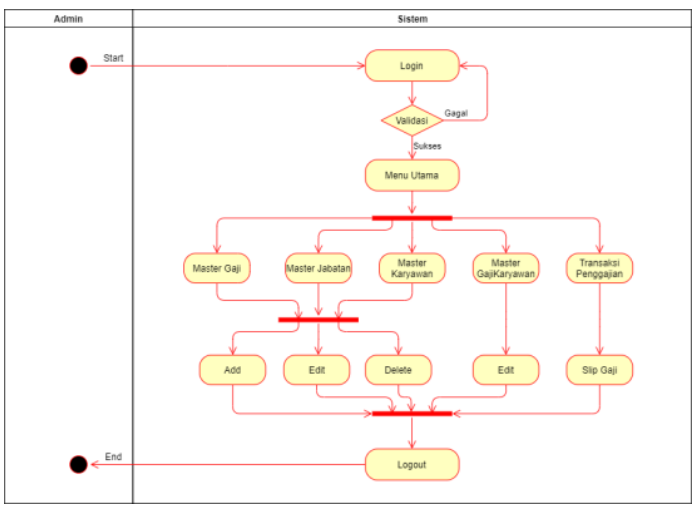

Gambar 3. 1 Activity Diagram

Administrator memulai aktivitas dengan $\log$ in. Jika tidak valid maka sistem akan menampilkan menu log in hingga valid. Setelah masuk, aplikasi sistem akan menampilkan halaman menu utama administrator. Administrator dapat memakai aplikasi sesuai hak aksesnya, yaitu memilih menambah data, mengubah data, maupun menghapus data.

\section{Class Diagram}

Class diagram merupakan diagram yang digunakan untuk menampilkan kelas-kelas yang ada dalam sistem yang berupa objek yang sedang dikembangkan dan dari kelas yang satu ke kelas yang lain yang mempunyai relasi. Class diagram terdiri dari nama kelas, atribut dan operasi dari kelas tersebut [6].

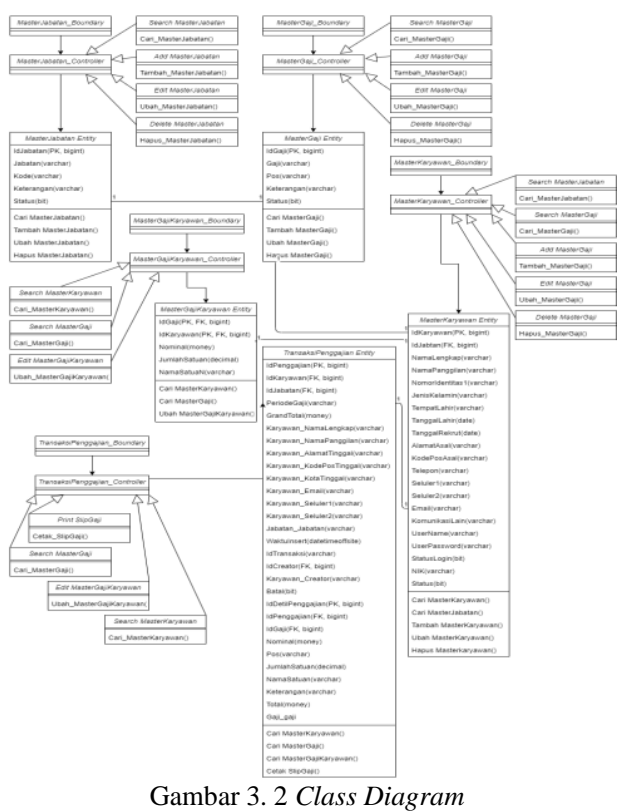

Seperti Gambar 3.4 yang merupakan class diagram pada Sistem Informasi Penggajian yang dirancang.

\section{HASIL DAN PEMBAHASAN}

Berikut ini akan dijelaskan tampilan antar muka dari sistem informasi penggajian karyawan Papua Barat Pos yang telah dibuat. Penjelasan akan dimulai dari menu master hingga menu transaksi penggajian dan cetak slip gaji. Berikut ini juga akan disertakan potongan serta penjelasan singkat mengenai fungsi yang ada pada segmen program tersebut.

Halaman Login

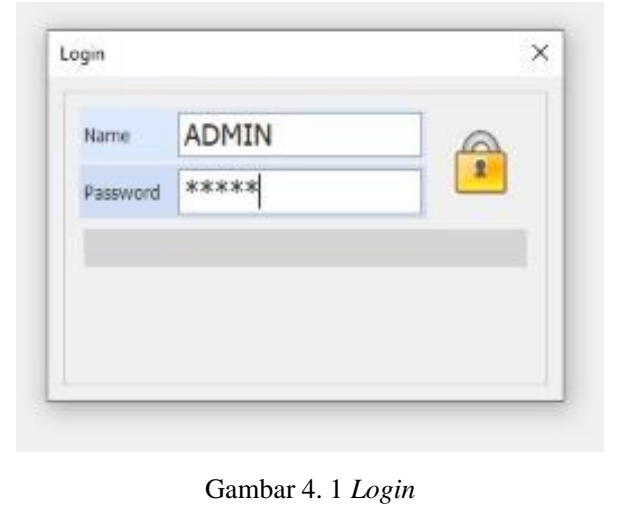

Gambar 4.1. ini merupakan tampilan yang akan muncul ketika aplikasi pertama kali dijalankan, yaitu form login. Seorang administrator harus memasukkan username dan password terlebih dahulu agar dapat melakukan akses pada aplikasi sistem informasi penggajian ini. 
Halaman Master Jabatan

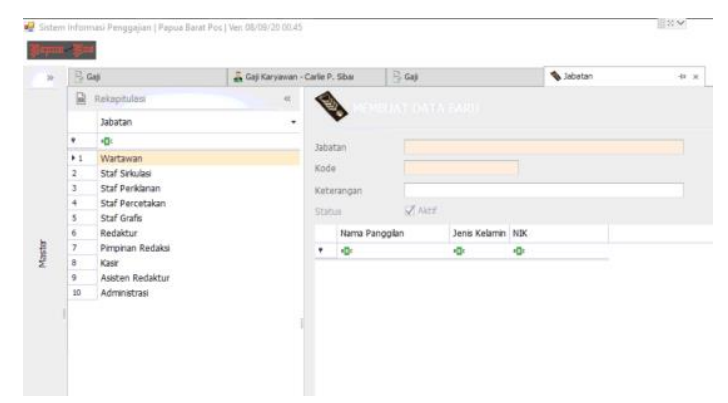

Gambar 4. 2 Form Master Jabatan

Gambar 4.2. merupakan tampilan dari halaman master jabatan yang akan ditampilkan pada saat admin membuka form master jabatan. Di dalam halaman ini terdapat daftar jabatan karyawan yang ada di Papua Barat Pos yaitu list jabatan yang ada di sebelah kiri. Ketika salah satu jenis jabatan diklik, maka akan muncul nama-nama karyawan dengan jabatan tersebut. Pada form ini, dapat dilakukan penambahan, editing, dan hapus jenis jabatan sesuai dengan kondisi pada Papua Barat Pos.

\section{Halaman Master Gaji}

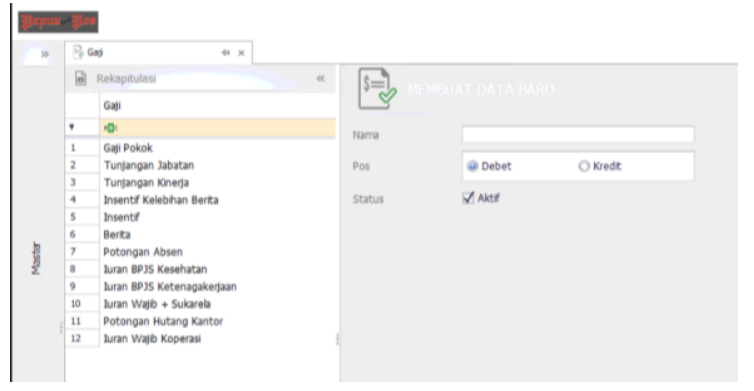

Gambar 4. 3 Form Master Gaji

Gambar 4.3. ini merupakan tampilan yang akan muncul ketika admin membuka halaman Gaji. Pada halaman ini ditampilkan jenis-jenis gaji karyawan yang ada di Papua Barat Pos. Apabila salah satu jenis gaji diklik, maka akan muncul informasi detil mengenai jenis gaji tersebut di sisi kanan. RadioButton Debit dan Kredit merupakan kondisi digunakan untuk membedakan penambahan atau pengurangan gaji, debit digunakan untuk penambahan gaji, sedangkan kredit digunakan untuk pengurangan gaji.

\section{Halaman Master Karyawan}

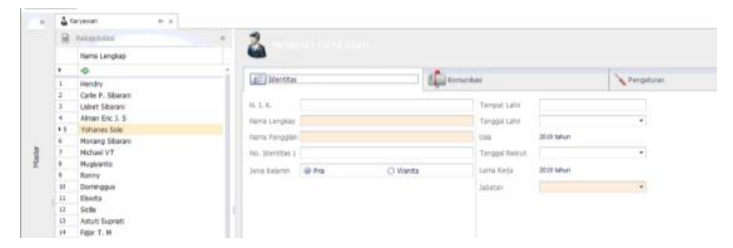

Gambar 4. 4 Form Master Karyawan
Gambar 4.4. ini merupakan tampilan dari halaman Karyawan. Halaman ini digunakan untuk menampilkan data pribadi semua karyawan Papua Barat Pos. Jadi, apabila nama salah satu karyawan yang ada pada sisi kiri diklik, maka akan menampilkan biodata lengkap karyawan tersebut pada sisi kanan. Data-data ini dapat di-edit maupun dihapus, admin juga dapat menambahkan data karyawan baru.

Halaman Master Gaji Karyawan

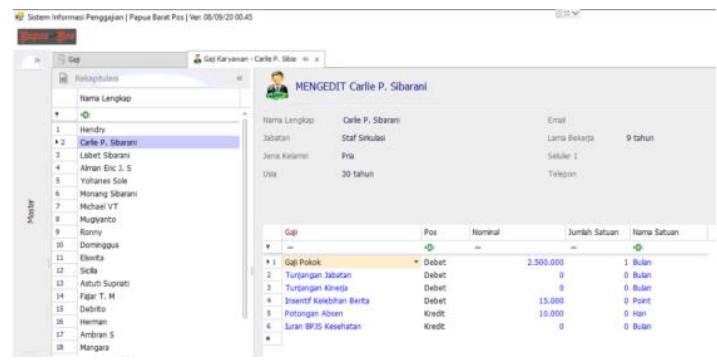

Gambar 4. 5 Form Master Gaji Karyawan

Halaman Transaksi Penggajian

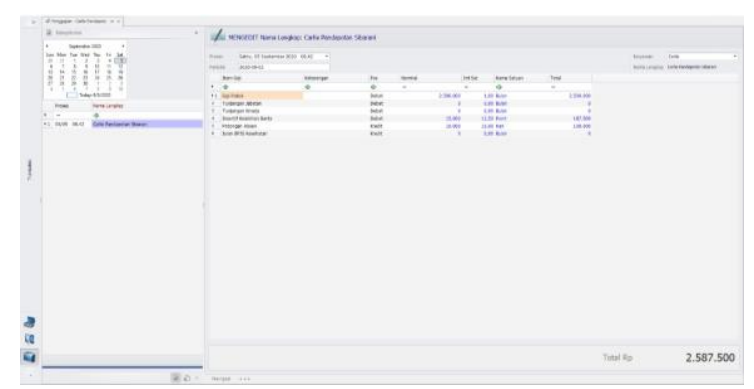

Gambar 4. 6 Form Transaksi Penggajian

Gambar 4.6. merupakan tampilan dari halaman transaksi penggajian. Halaman ini menampilkan detil gaji karyawan beserta nominalnya, sehingga akan diketahui jumlah gaji bersih yang diperoleh oleh karyawan tersebut. Ketika data ini disimpan, maka ia akan tersimpan pada tabel sebelah kiri yaitu tabel T6Penggajian. Dari halaman ini juga dapat dilakukan proses cetak/print slip gaji karyawan dengan tampilan slip gaji seperti gambar 4.7. 


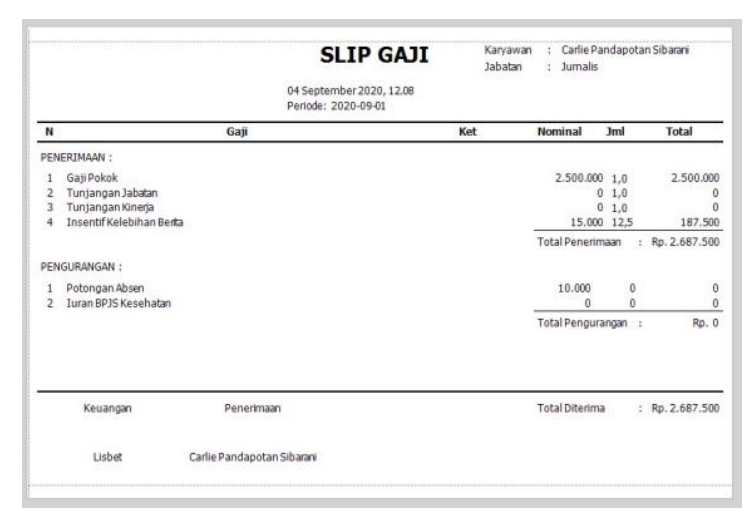

Gambar 4. 7 Tampilan Slip Gaji

\section{KESIMPULAN}

Kesimpulan dari penelitian yang dilakukan adalah Sistem informasi penggajian yang rancang telah berhasil melakukan proses penghitungan gaji karyawan secara cepat, tepat dan akurat secara otomatis. Sistem informasi ini telah berhasil melakukan cetak slip gaji secara otomatis, hal ini pastinya meminimalisir adanya human error dan mempercepat proses transaksi penggajian jika dibandingkan dengan cara manual.

Saran untuk pengembangan sistem adalah aplikasi ini diharapkan dapat dikembangkan lagi tidak hanya berbasis desktop, namun menjadi sistem informasi berbasis web agar pengolahan data dapat dilakukan dimanapun dan kapanpun. Sistem informasi saat ini hanya dibangun untuk proses transaksi penggajian karyawan saja, diharapkan nantinya sistem ini dapat dikembangkan dengan meliputi sistem-sistem manual lainnya yang ada pada kantor redaksi Papua Barat Pos.

\section{DAFTAR PUSTAKA}

[1] B. S. D. Oetomo and S. Kom, "Perencanaan \& Pembangunan Sistem Informasi,” 2002.

[2] M. Noviyani, "Sistem Informasi Penggajian Pegawai Madrasah Aliyah Negeri Binjai," Universitas Sumatera Utara, 2009.

[3] R. S. Pressman and B. R. Maxim, Software Engineering: A Practitioner's Approach, Eighth Edition, vol. 66. 2015.

[4] F. G. J. Rupilele et al., "Management information system for monitoring and inspection of the implementation of Universities," Int. J. Eng. Technol., 2018, doi: 10.14419/ijet.v7i2.13.18138.

[5] F. G. john Rupilele and A. Palilu, "Rancang Bangun Sistem Informasi Manajemen Pengaduan Masyarakat dan Monitoring Kinerja Akademik Perguruan Tinggi," $J$. Sisfokom (Sistem Inf. dan Komputer), 2019, doi: 10.32736/sisfokom.v8i2.672.
[6] F. G. john Rupilele, "Perancangan Sistem Informasi Manajemen Pelayanan Anggota Jemaat, Baptisan, dan Pernikahan Berbasis Web (Studi Kasus: Gekari Lembah Pujian Kota Sorong)," J. Teknol. Inf. dan Ilmu Komput., 2018, doi: 10.25126/jtiik.201852685.

[7] T. N. Lina, M. S. Rumetna, F. G. J. Rupilele, A. N. S. Palisoa, and M. Z. Sirajjudin, "Sistem Informasi E-Arsip Berbasis Web (Studi Kasus: PT Haleyora Powerindo Cabang Sorong)," J. Jendela Ilmu, vol. 1, no. 1, pp. 1-5, 2020.

[8] F. G. J. Rupilele and F. Singgir, "Perancangan Sistem Informasi Pengolahan Nilai Siswa Berbasis Web Pada Sekolah Menengah Pertama Negeri 10 Kota Sorong," J. Jendela Ilmu, vol. 1, no. 2, pp. 75-79, 2020. 